Research Article

\title{
Design of a Decision Support System for Functional Beverage Flavoring
}

Ariya Ounsri* and Pornthip Tabkosai

Department of Industrial Engineering, Faculty of Engineering, King Mongkut's University of Technology North Bangkok, Bangkok, Thailand

Athakorn Kengpol

Advanced Industrial Engineering Management Systems Research Center, Department of Industrial Engineering, Faculty of Engineering, King Mongkut's University of Technology North Bangkok, Bangkok, Thailand

Sopida Tuammee

College of Industrial Technology, Department of Information and Production Technology Management, King Mongkut's University of Technology North Bangkok, Bangkok, Thailand

* Corresponding author. E-mail: ariyaounsri@hotmail.comＤOI: 10.14416/j.ijast.2018.12.006

Received: 21 February 2018; Revised: 25 April 2018; Accepted: 5 June 2018; Published online: 25 December 2018 (C) 2020 King Mongkut's University of Technology North Bangkok. All Rights Reserved.

\begin{abstract}
The objective of research is to design and develop a Decision Support System (DSS) software to assess customer satisfaction on functional beverage flavor notes. Questionnaire is launched to gather data of costumer preference. The taste, color and odor are the subjects of questionnaire. Data is acquired from 400 customers in six groups from North, North Eastern, Central, Southern, and Bangkok of Thailand that have different gender and age. The survey shows that there are 5 well known tastes of functional drinks which are mango, passion fruit, Thai blueberry, linhzhi and mangosteen in both level of concentration (100\% and mixed). The DSS is analyzed by using ANN in comparison with hybrid Artificial Neural Network and Particle Swarm Optimization (ANN-PSO). Both models give the same results shown in structure (6-18-30). The minimum MSE is 0.0054784 at 6 epochs. As a result of comparison between two models, the result shows that minimum speed time of ANN-PSO faster than ANNs. Hence, ANN-PSO is an appropriate system for using in the DSS software.
\end{abstract}

Keywords: Functional beverage, Hybrid Artificial Neural Network (ANN) with particle Swarm Optimization (ANN-PSO), Decision Support System (DSS)

\section{Introduction}

Functional drink is a drink typically intended to convey a health benefit. Some include ingredients like herbs, vitamins, minerals, amino acids, or additional raw fruit or vegetables. Thus, the marketing is spreading from combined consumer groups to the middle-age and elderly group. The objective of this research is to design and develop a Decision Support System (DSS) software to assess customer satisfaction on functional beverage flavor notes.

According to the recent research from Ceballos [1], ANN model is chosen due to its learning ability, however, the computational time is considerably high, Leung et al. [2] suggest to combine ANN with PSO model. The hybrid ANN-PSO models can obtain quicker results. 


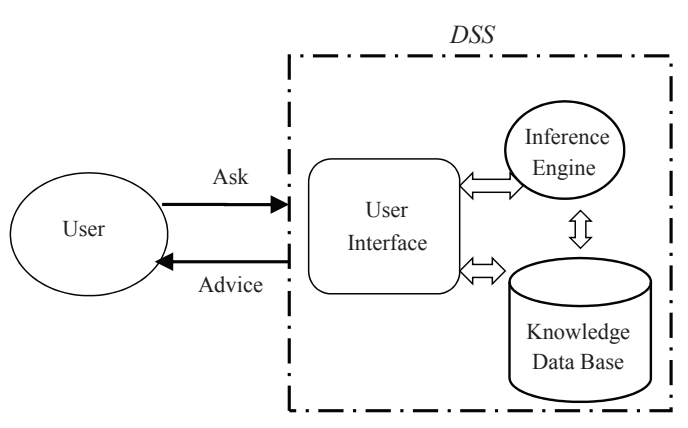

Figure 1: The structure of DSS [4].

\section{Literature Review}

There are 4 sections, such as Flavoring agent, Decision Support System, Artificial Neural Networks and Particle Swarm Optimization.

\subsection{Flavoring agent}

Flavoring agent is important for taste of the food and drink. It can be sectioned into 3 groups such as 1) fruity notes 2) scent and 3) other notes.

Mixing flavoring agent is tested by using expert and high experienced people about odor smell by their noses to find and use as key compounds for mixing to make flavoring agent that is called "key volatile compound". Mixing flavoring agent can be analyzed by using a machine called "Gas Chromatography-Mass Spectrometry (GC-MS)". [3]

\subsection{Decision Support System (DSS)}

A Decision Support System (DSS) is a computer application program that analyzes business data and presents it so that users can make business decisions easily. It is an "informational application". The DSS can integrate multiple variables and generate an outcome and alternated outcomes, all based upon the user's past data and current variables. [4]

The structure of DSS is shown in Figure 1.

\subsection{Artificial Neural Network (ANN)}

An Artificial Neural Network (ANN) is a computational model based upon the structure and functions of biological neural networks. Information that flows through the network affects the structure of the ANN

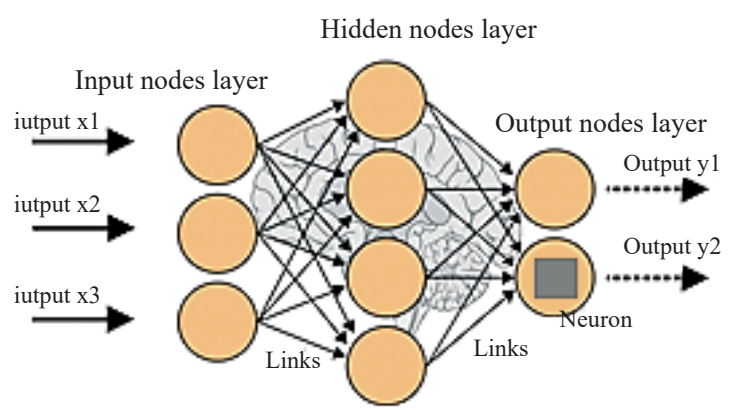

Figure 2: The structure of ANNs.

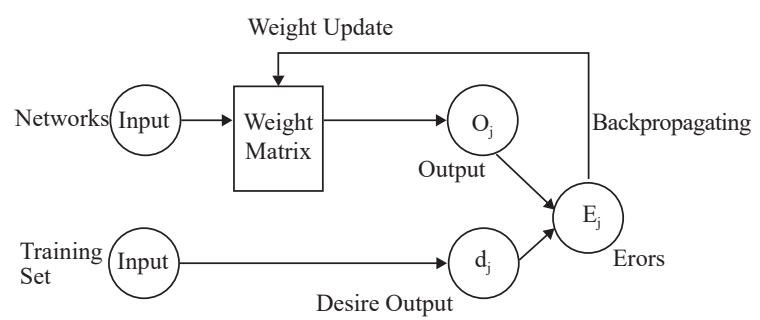

Figure 3: The structure of BPNNs.

because a neural network changes or learns in based on that input and output.

Figure 2 demonstrates ANN Structure. ANN neural networks are typically organized in layers. Layers are made up of a number of connected 'nodes' which contain an "activation function". Patterns are presented to the network via the "input layer", which communicates to one or more "hidden layers" where the actual processing is done via a system of weighted "connections". The hidden layers then link to an "output layer". Figure 3 divides layers that Input Layer as called " $\mathrm{X}_{\mathrm{n}}$ " is input node multiplied with " $\mathrm{W}_{\mathrm{n}}$ " and summation in the Equation (1).

$\mathrm{U}_{\mathrm{n}}=\sum\left(\mathrm{X}_{\mathrm{n}} * \mathrm{~W}_{\mathrm{n}}\right)$

Hidden layer can be solved with transfer function. The frequent using is Log-sigmoid Equation (2). Output Layer is " $y$ ". Although, there are many different kinds of learning rules used by ANN, the well-known learning rules are called "back-propagation neural networks" (BPNNs). [4], [5].

The BPNNs investigate error from Equation (2) and adjust weight with iteration or called "epoch". Finally, the model stops when minimum error is obtained [6]. 


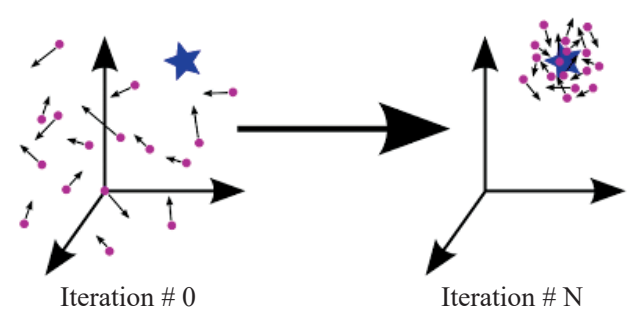

Figure 4: PSO (Adapted from [2]).

$e_{j}(n)=d_{j}(n)-o_{j}(n)$

" $d_{j}$ " is output training.

" $O_{j}$ " is output testing.

\subsection{Particle Swarm Optimization (PSO)}

Particle Swarm Optimization (PSO) is a population based stochastic optimization technique. This module is inspired by social behavior of bird flocking or fish schooling. The algorithm keeps track of 3 global variables 1) Target value or condition, 2) Global best (gBest) value indicating which particle's data is currently closest to the Target, 3) Stopping value indicating when the algorithm should stop if the Target isn't found. It shows in Figure 4 and Solution of PSO Show in the Equations (3) and (4).

$v_{i d}(t+1)=w(t) v_{i d}(t)+c_{p} u\left(p_{i d}-x_{i d}(t)\right)+c_{g} u\left(p_{g d}-x(t)\right)$

$v_{i d}(t+1)=\left\{\begin{array}{l}-V_{\max } \text { if } v_{i d}(t+1) \leq-V_{\max } \\ V_{\max } \text { if } v_{i d}(t+1) \geq V_{\max }\end{array}\right.$

$x_{i d}(t+1)=x_{i d}(t)+v_{i d}(t+1)$

" $V$ id" is velocity of particle, " $t$ " is iteration, " $w$ " is inertia weight (appropriate value is 1 ), " $c_{p}$ " and " $c_{g}$ " is acceleration constant (appropriate value is $c_{p}=c_{g}=2$ ), " $P_{g d}$ " is global best position, " $P_{i d}$ " is personal best position. The Equation (3) gives new velocity to fine position of particle is " $X_{i d}$ ". PSO can be hybrid with ANNs (ANN-PSO) when " $X$ id" is weight in ANN and " $V$ id" is velocity of weight in ANN to solve at setting iteration. ANN-PSO can investigate appropriate weight by the error in the Equation (2). [7]

\section{Research Methodology}

Figure 5 presents research methodology in 6 sections.

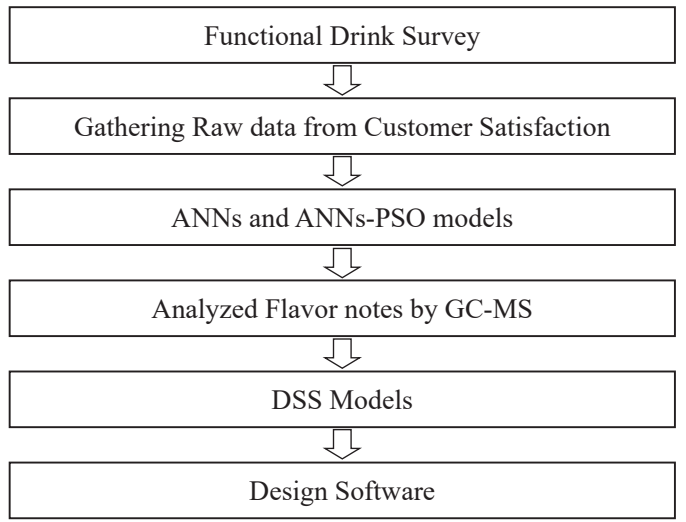

Figure 5: Research Methodology.

\subsection{Functional drink survey}

Functional drinks can be selected from the list of beverage made in Thailand. This research selects 5 most popular tastes with two levels of concentration (100\% and mixed fruit juice).

\subsection{Gathering raw data from customer satisfaction}

A questionnaire is created to survey customer satisfaction. This questionnaire can obtain information about the customer (gender, age) and gather score on a 5-point Likert scale. The reliability is tested by using Cronbach alpha coefficient.

\subsection{ANN and hybrid ANN-PSO models}

In this research, ANN model and Hybrid ANN-PSO model are applied in the methodology. The application of ANN and ANN-PSO can suggest an appropriate flavor notes (taste, odor and color) for different group of customer.

\subsection{Flavor notes analyzed by using GC-MS}

The GC-MS machine can identify the key volatile compound of the flavor notes.

\subsection{DSS models}

The DSS are composed by input layers, hidden layer, output layer with minimum MSE including different types of the key volatile compounds from each flavor 


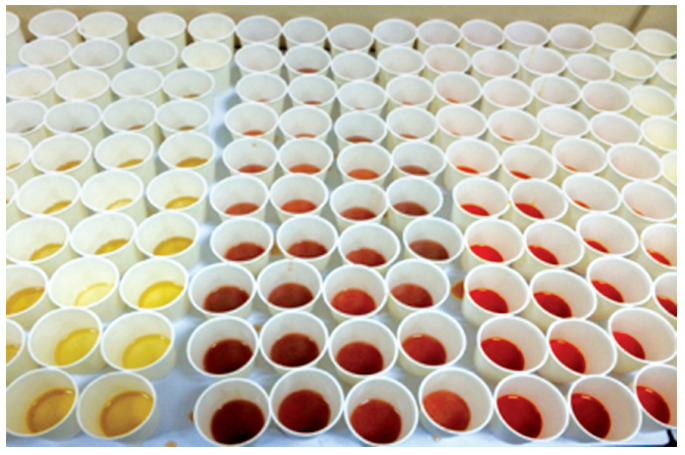

Figure 6: List of beverage notes.

notes. The DSS can generate a prediction of flavor notes in accordance with different group of customer.

\subsection{Design DSS software}

The DSS software is developed by using Visual Studio 2015 and writing in C\# and choose the optimal model.

\section{Results}

\subsection{Choosing functional drink and analysed by GC-MS}

This research chooses 10 popular Functional Drink notes from the list of beverage notes that made in Thailand. There are 1) mango, 2) mango mixed, 3) passion fruit, 4) passion fruitmixed, 5) Thai blueberry, 6) Thaiblueberry mixed, 7) linhzhi, 8) linhzhi mixed, 9) mangosteen and 10) mangosteen mixed. Each 10 key functional beverage flavor notes are classified into 3 sub-classes (taste, odor and color). There are shown in Figure 6.

Key volatile compound in Functional Drink is analysed by using GC-MS. It shows in Table 1 .

Next step, using GC-MS machine and Brix Refractometer, the functional drink can be analyzed about sugar, \%brix and citric acid, as shown in Table 2.

Table 1: Key volatile compounds

\begin{tabular}{|l|l|}
\hline \multicolumn{1}{|c|}{ Taste } & \multicolumn{1}{c|}{ Key Volatile Compounds } \\
\hline \multirow{3}{*}{ Mango } & $\begin{array}{l}\text { Ethyl-2-methylpropanoate, Ethyl Butanoate, } \\
\text { (E, Z)-2, 6-nonadienal, (E)-2-nonenal, } \\
\text { Methyl Benzoate, (E)- } \beta \text {-ionone, Decanal, } \\
\text { 2, 5-dimethyl-4-methoxy-3(2H)-furanone }\end{array}$ \\
\hline Passion fruit & ethyl butanoate, ethyl hexanoate, $\beta$-ionone \\
\hline Thai blueberry & Linalool, (E)-2-hexenal \\
\hline Linhzhi & 1-octen-3-ol \\
\hline Mangosteen & Longifolene \\
\hline
\end{tabular}

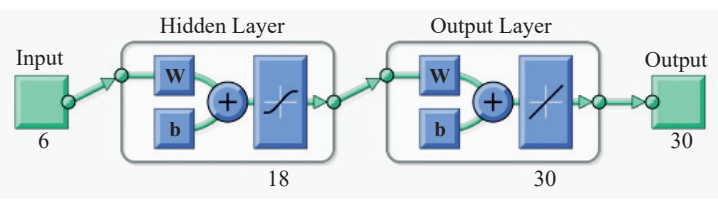

Figure 7: ANNs and ANNs-PSO model.

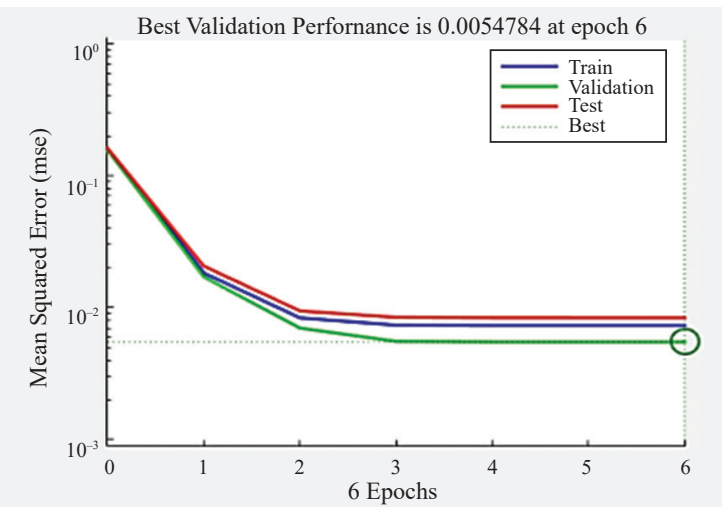

Figure 8: minimum MSE.

Table 2: The functional drink can be analyzed about sugar, \%brix and citric acid

\begin{tabular}{|l|c|c|c|c|c|c|}
\hline \multicolumn{1}{|c|}{ Drink } & $\begin{array}{c}\text { Glucose } \\
(\mathbf{g})\end{array}$ & $\begin{array}{c}\text { Fructose } \\
(\mathbf{g})\end{array}$ & $\begin{array}{c}\text { Sucrose } \\
(\mathbf{g})\end{array}$ & $\begin{array}{c}\text { Sugar } \\
(\mathbf{g})\end{array}$ & $\begin{array}{c}\text { \%brix } \\
(\mathbf{0 b r i x})\end{array}$ & $\begin{array}{c}\text { Citric Acid } \\
(\mathbf{\%} \text { V/V) }\end{array}$ \\
\hline Mango 100\% & 3.76 & 3.8 & 0.46 & 8.02 & 14.00 & 0.40 \\
\hline Mango mixed & 4.07 & 3.7 & - & 7.81 & 14.60 & 0.70 \\
\hline $\begin{array}{l}\text { Passion fruit } \\
100 \%\end{array}$ & 2.96 & 2.9 & 0.28 & 6.16 & 12.50 & 0.69 \\
\hline $\begin{array}{l}\text { Passion fruit } \\
\text { mixed }\end{array}$ & 2.97 & 3.0 & 0.93 & 6.92 & 11.80 & 0.68 \\
\hline $\begin{array}{l}\text { Thai blueberry } \\
100 \%\end{array}$ & 3.53 & 2.7 & - & 6.46 & 17.0 & 0.93 \\
\hline $\begin{array}{l}\text { Thaiblueberry } \\
\text { mixed }\end{array}$ & 4.34 & 3.7 & 0.02 & 8.12 & 14.0 & 0.47 \\
\hline Linhzhi 100\% & 1.72 & 2.4 & 0.67 & 4.79 & 7.10 & 0.02 \\
\hline Linhzhi mixed & 0.93 & 2.5 & - & 3.45 & 3 & 0.01 \\
\hline $\begin{array}{l}\text { Mangosteen } \\
100 \%\end{array}$ & 4.52 & 3.6 & 0.02 & 8.24 & 16.1 & 0.45 \\
\hline $\begin{array}{l}\text { Mangosteen } \\
\text { mixed }\end{array}$ & 2.04 & 2.5 & 0.04 & 4.65 & 8 & 0.25 \\
\hline
\end{tabular}

\subsection{Design and compare ANN with Hybrid ANN- PSO}

After gathering data from customer, according to database in ANN model and hybrid ANN-PSO model, both of the models result in the same structure (6-18-30), minimum MSE is 0.0054784 at 6 epochs and result of favorite. There have been shown in Figures 7 and 8, respectively. The preferred functional drink is shown in Table 3. 
Table 3: Preferred functional drink of customer

\begin{tabular}{|c|c|c|c|c|c|c|}
\hline \multirow{2}{*}{$\begin{array}{c}\text { Functional } \\
\text { Drink }\end{array}$} & \multicolumn{3}{|c|}{ Man } & \multicolumn{3}{|c|}{ Woman } \\
\hline & Teen & Adult & Older & Teen & Adult & Older \\
\hline Taste mango $100 \%$ & 0.3551 & 0.3294 & 0.3263 & 0.3227 & 0.3216 & 0.3151 \\
\hline Odor mango $100 \%$ & 0.3397 & 0.3103 & 0.3318 & 0.3012 & 0.3257 & 0.3146 \\
\hline Color mango $100 \%$ & 0.3802 & 0.3194 & 0.3203 & 0.3321 & 0.3387 & 0.3180 \\
\hline Taste mango mixed & 0.4212 & 0.3279 & 0.3265 & 0.3181 & 0.3243 & 0.3228 \\
\hline Odor mango mixed & 0.3900 & 0.3100 & 0.3069 & 0.3072 & 0.3014 & 0.3072 \\
\hline Color mango mixed & 0.4204 & 0.3235 & 0.3142 & 0.3280 & 0.3192 & 0.3110 \\
\hline $\begin{array}{l}\text { Taste passion fruit } \\
100 \%\end{array}$ & 0.3262 & 0.3688 & 0.4339 & 0.3341 & 0.3227 & 0.3193 \\
\hline $\begin{array}{l}\text { Odor passion fruit } \\
100 \%\end{array}$ & 0.3229 & 0.3660 & 0.4142 & 0.3263 & 0.3101 & 0.2979 \\
\hline $\begin{array}{l}\text { Color passion fruit } \\
100 \%\end{array}$ & 0.3194 & 0.3798 & 0.4226 & 0.3450 & 0.2939 & 0.3031 \\
\hline $\begin{array}{l}\text { Taste passion fruit } \\
\text { mixed }\end{array}$ & 0.2721 & 0.4269 & 0.3926 & 0.2979 & 0.3036 & 0.3091 \\
\hline $\begin{array}{l}\text { Odor passion fruit } \\
\text { mixed }\end{array}$ & 0.2699 & 0.4110 & 0.3793 & 0.3086 & 0.2815 & 0.2927 \\
\hline $\begin{array}{l}\text { Color passion fruit } \\
\text { mixed }\end{array}$ & 0.2901 & 0.4288 & 0.3942 & 0.3233 & 0.3153 & 0.3002 \\
\hline $\begin{array}{l}\text { Taste blueberry } \\
100 \%\end{array}$ & 0.2618 & 0.2984 & 0.3249 & 0.3774 & 0.3521 & 0.3068 \\
\hline $\begin{array}{l}\text { Odor blueberry } \\
100 \%\end{array}$ & 0.2344 & 0.2686 & 0.3151 & 0.3630 & 0.3513 & 0.2876 \\
\hline $\begin{array}{l}\text { Color blueberry } \\
100 \%\end{array}$ & 0.2927 & 0.2723 & 0.3232 & 0.4276 & 0.4071 & 0.2948 \\
\hline $\begin{array}{l}\text { Taste blueberry } \\
\text { mixed }\end{array}$ & 0.3184 & 0.2925 & 0.3258 & 0.3631 & 0.4429 & 0.3236 \\
\hline $\begin{array}{l}\text { Odor blueberry } \\
\text { mixed }\end{array}$ & 0.2827 & 0.2671 & 0.3028 & 0.3359 & 0.3879 & 0.3005 \\
\hline $\begin{array}{l}\text { Color blueberry } \\
\text { mixed }\end{array}$ & 0.3231 & 0.2825 & 0.3088 & 0.3698 & 0.4371 & 0.3118 \\
\hline $\begin{array}{l}\text { Taste linhzhi } \\
100 \%\end{array}$ & 0.3110 & 0.2660 & 0.3019 & 0.2901 & 0.2989 & 0.3149 \\
\hline Odor linhzhi $100 \%$ & 0.2957 & 0.2755 & 0.2975 & 0.2929 & 0.2707 & 0.3085 \\
\hline $\begin{array}{l}\text { Color linhzhi } \\
100 \%\end{array}$ & 0.3082 & 0.2808 & 0.2911 & 0.3111 & 0.2963 & 0.3200 \\
\hline Taste linhzhi mixed & 0.2831 & 0.2708 & 0.2689 & 0.2882 & 0.2689 & 0.2980 \\
\hline Odor linhzhi mixed & 0.2642 & 0.2652 & 0.2633 & 0.2832 & 0.2439 & 0.2958 \\
\hline Color linhzhi mixed & 0.2844 & 0.2709 & 0.2777 & 0.3070 & 0.2807 & 0.3097 \\
\hline $\begin{array}{l}\text { Taste mangosteen } \\
100 \%\end{array}$ & 0.2884 & 0.2988 & 0.3280 & 0.3101 & 0.2776 & 0.4530 \\
\hline $\begin{array}{l}\text { Odor mangosteen } \\
100 \%\end{array}$ & 0.2838 & 0.2838 & 0.3169 & 0.2845 & 0.2457 & 0.4210 \\
\hline $\begin{array}{l}\text { Color mangosteen } \\
100 \%\end{array}$ & 0.2941 & 0.2882 & 0.3247 & 0.2852 & 0.2788 & 0.4206 \\
\hline $\begin{array}{l}\text { Taste mangosteen } \\
\text { mixed }\end{array}$ & 0.2732 & 0.2765 & 0.3056 & 0.3019 & 0.2782 & 0.3598 \\
\hline $\begin{array}{l}\text { Odor mangosteen } \\
\text { mixed }\end{array}$ & 0.2666 & 0.2593 & 0.322 & 0.2700 & 0.2591 & 0.3501 \\
\hline $\begin{array}{l}\text { Color mangosteen } \\
\text { mixed }\end{array}$ & 0.2796 & 0.2676 & 0.3239 & 0.2985 & 0.2663 & 0.3654 \\
\hline
\end{tabular}

*blue color means the most of favorite

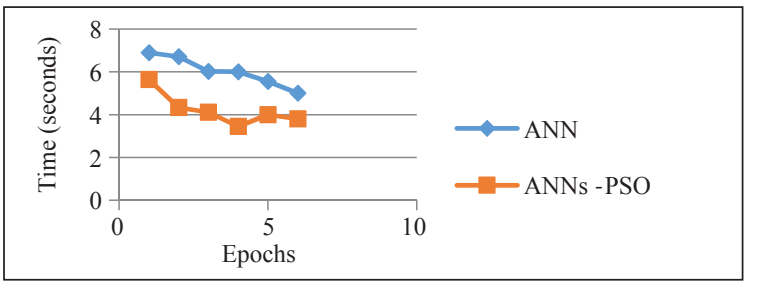

Figure 9: Comparing speed time.

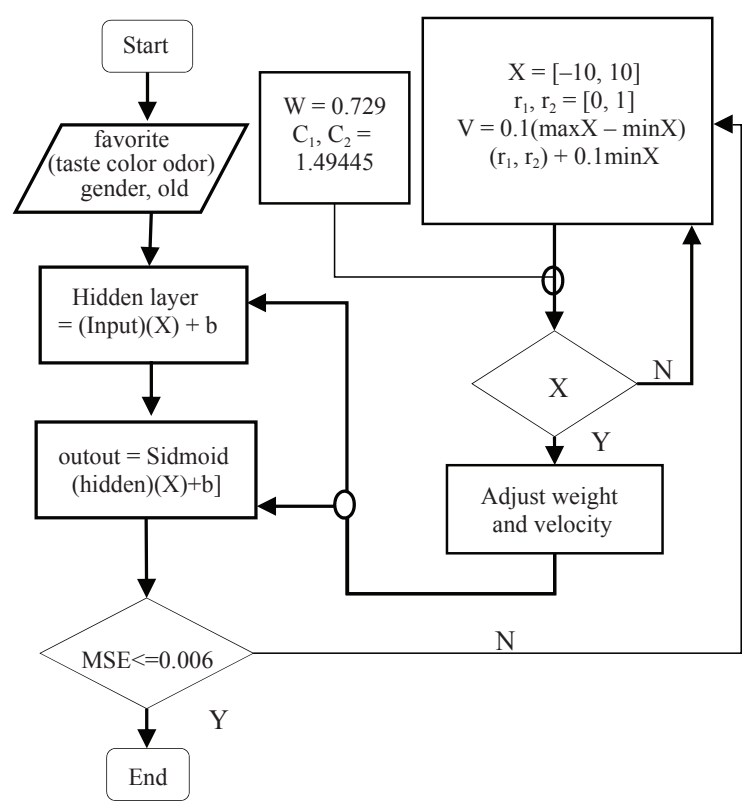

Figure 10: Hybrid ANN-PSO.

When compared both models, the results show that minimum speed time of hybrid ANN-PSO faster than ANN. Hence, this is the reason why this research chooses hybrid ANN-PSO model in the DSS software (Figure 9).

\subsection{DSS Software}

The DSS Software is created by using Visual Studio with ANN-PSO algorithm as shown in Figure 10 and Figure 11 presents also the user interface of software.

\section{Conclusions}

The objective of research is to design and develop a Decision Support System (DSS) software to assess customer satisfaction on functional beverage flavor notes. The results show that hybrid ANN-PSO 


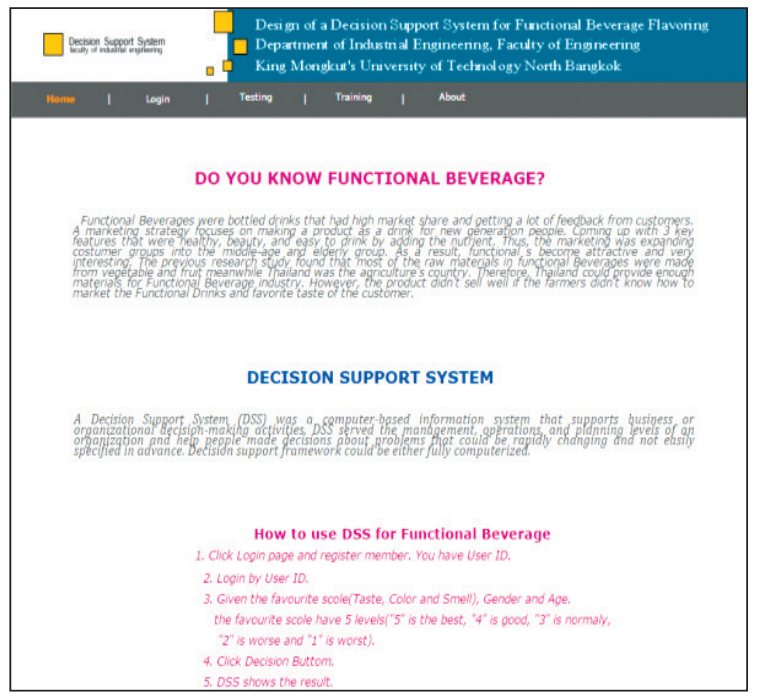

Figure 11: DSS Software.

can present a better off result due to lower optimal computational time when compared with ANN. The appropriate structure is muti-layer feed forward with 6-18-30 structure, by 6 nodes of customer groups at the input layer, 30 nodes of flavor notes at the output layer and 18 nodes of hidden layer selected with minimum MSE (0.0054784). Further research can be done to improve the database which can be seen in [8].

\section{Acknowledgments}

The authors would like to express sincere gratitude to Mahidol University for allowing us to use GC-MS and Brix Refractometer machine, and also people who provided valuable time and information for this research but the name unfortunately cannot be revealed because of the confidentiality agreement. The authors are also very appreciative of all of the anonymous reviewers for their valuable comments. This research was funded by King Mongkut's University of Technology North Bangkok. Contract no. KMUTNBNRU-58-05.

\section{References}

[1] M. Ceballos, "Characterisation of tequila according to their major volatile composition using multilayer perceptron neural networks," Food Chemistry, vol. 136, pp. 1309-1315, Feb. 2013.

[2] S. Leung, Y. Tang, and W. Wong, “A hybrid particle swarm optimization and its application in neural networks," Expert Systems with Applications, vol. 39, pp. 395-405, Jan. 2012.

[3] T. C. Union Global Public Company Limited. (2009, Jan.). The functional drink of marketing versus demand. T. C. Union Global Public Company Limited. Bangkok, Thailand [Online]. Available: https://positioningmag.com/11474 (in Thai)

[4] A. Kengpol and W. Wangkananon, "An assessment of customer contentment for ready-to-drink tea flavour notes using artificial neural networks," Toward Sustainable Operations of Supply Chain and Logistics Systems. Part of the Series EcoProduction, vol. 1, pp. 421-434, Jan. 2015.

[5] A. Kengpol, S. Tuamee, and W. Meethom "Design of a decision support system on selection of multimodal transportation with environmental consideration between Thailand and Vietnam," KMUTNB International Journal of Applied Science and Technology, vol. 5, pp. 55-63, Feb. 2012.

[6] A. Kengpol and W. Wangkananon, "The expert system for assessing customer satisfaction on fragrance notes: Using artificial neural networks," Computers \& Industrial Engineering, vol. 51, pp. 567-584, Jan. 2006.

[7] A. J. Danial, "Developing a hybrid PSO-ANN model for estimating the ultimate bearing capacity of rock-socketed piles," Neural Computing and Applications, vol. 28, pp. 391-405, Feb. 2017.

[8] P. Tabkosai and A. Kengpol, "The development of a database management for product development: A case study in a wire harness manufacturer", presented at the IE Network, Khonkan, Thailand, Jul. 7-8, 2016. 